\title{
New public spaces as the basic nodes for development of new city areas (case study of Kronstadt, Russia)
}

\author{
Olga Kokorina ${ }^{1, *}$, Dmitry Zinenkov ${ }^{1}$, and Tamara Datsuk ${ }^{1}$ \\ ${ }^{1}$ State University of Architecture and Civil Engineering, 190005, St. Petersburg, Russia
}

\begin{abstract}
The article presents research materials and analysis of factors affecting the creation of new nodes of public spaces, as starting points for the development of Kotlin Island and the city of Kronstadt. Their current state and problems, resources and opportunities are described. Currently, there is a process of rethinking the value of the coastal territories of Kronstadt, the potential of which is not realized. One of the possible ways to solve this problem is to increase the use of coastal territories by creating tourism and public-business infrastructure along the coastline. Kronstadt has a number of unique characteristics, the use of which can transfer it from degrading to developing. This is possible by creating a polycentric model in the city - new growth points, as well as rethinking the value of abandoned and coastal territories. This approach will not only increase funding, attract more people, provide a sufficient number of jobs, but also subsequently create conditions for the further development of the city as an independent unit - the center of the St. Petersburg metropolitan area.
\end{abstract}

\section{Introduction}

World trends in urban development indicate an increase in the growth of large urban agglomerations, developing as a rule monocentrically - with the formation of the core of the agglomeration and the surrounding satellite cities. This principle of development entails a number of problems, one of which is the oversaturation of the city center with transport, human, information and economic flows. At the same time, the surrounding satellite cities are often lagging behind in development. However, many of the cities included in the agglomeration have unique characteristics and qualities, the development of which can turn them into polycentres, which are full links in this system.

On the example of the St. Petersburg agglomeration under consideration, one of these cities is Kronstadt. This island city has a unique preserved historical and rich natural landscape. At the moment, the city is one of the least populated and has the smallest budget from all areas of St. Petersburg [1].

\footnotetext{
* Corresponding author: olga.kokorina@gmail.com
} 


\section{Materials and methods}

In the work on identifying potential points of attraction for Kronstadt, a field study, cartographic analysis, and analysis of geographic information systems were performed. As a result of this work, the following were compiled: a reference plan, transport schemes, functional schemes, landscaping schemes, a scheme of accessibility of the territory, schemes of social and business activity and points of attraction, and others.

\section{Results and discussions}

\subsection{The historical potential of the territory}

Historically, the island of Kotlin has had borderline importance between Sweden and Novgorod lands. The emergence of the city is associated with the need to protect the mouth of the Neva and laid in 1703. St. Petersburg from attacks from the sea [6]. The first building was the fortress Kronshlot, designed by Domenico Trezzini. In 1723, Peter I laid the fortress of Kronstadt. Gradually, port harbors were built on the island, docks were built, factories and workshops were built, which exist to this day. Kotlin became the main military base of the Russian navy in the Baltic Sea. From the very beginning, Kronstadt was built on a model similar to the Petersburg city planning model with a clear planning structure and a rectangular street grid [6]. During the recovery period after the flood of 1824. many buildings of historical importance for the city were built. In the revolutionary period, Kronstadt is famous for the armed uprising of 1921. During the Great Patriotic War, the city, like St. Petersburg, found itself in a blockade along with the entire Baltic Fleet. After the war, the city was rebuilt. In 1984, as a result of the construction of the dam, the island of Kotlin on the north side was connected to the mainland by a highway. Since Soviet times, Kronstadt has been a completely closed city, since there were many military and strategically important facilities. Only in 1996, the city was open to the public. In 1990, the historical center of the city was included in the UNESCO World Heritage List as an integral part of the "Historical Center of St. Petersburg and its associated complexes of monuments".

\subsection{The current state of the island of Kotlin}

In the city of Kronstadt there is a shortage of green spaces for public use [9]. The island position of the city determines the peculiarity of its transport accessibility, which today is provided only through the complex of protective structures on which the ring road (KAD) is located (Fig. 1). The city is connected with the Ring Road through a single highway - the Kronstadt highway. It is planned to create another congress in the northern part to promising alluvial territories. Today, the most attractive for tourists and residents of the city are Anchor Square with the Marine St. Nicholas Cathedral, Lenin Avenue - the main shopping street, the embankment in the southern part of the city, including Petrovsky Park and Petrovsky Dock. Coastal spaces have high aesthetic characteristics, but landscaping and lighting are minimal or nonexistent. 


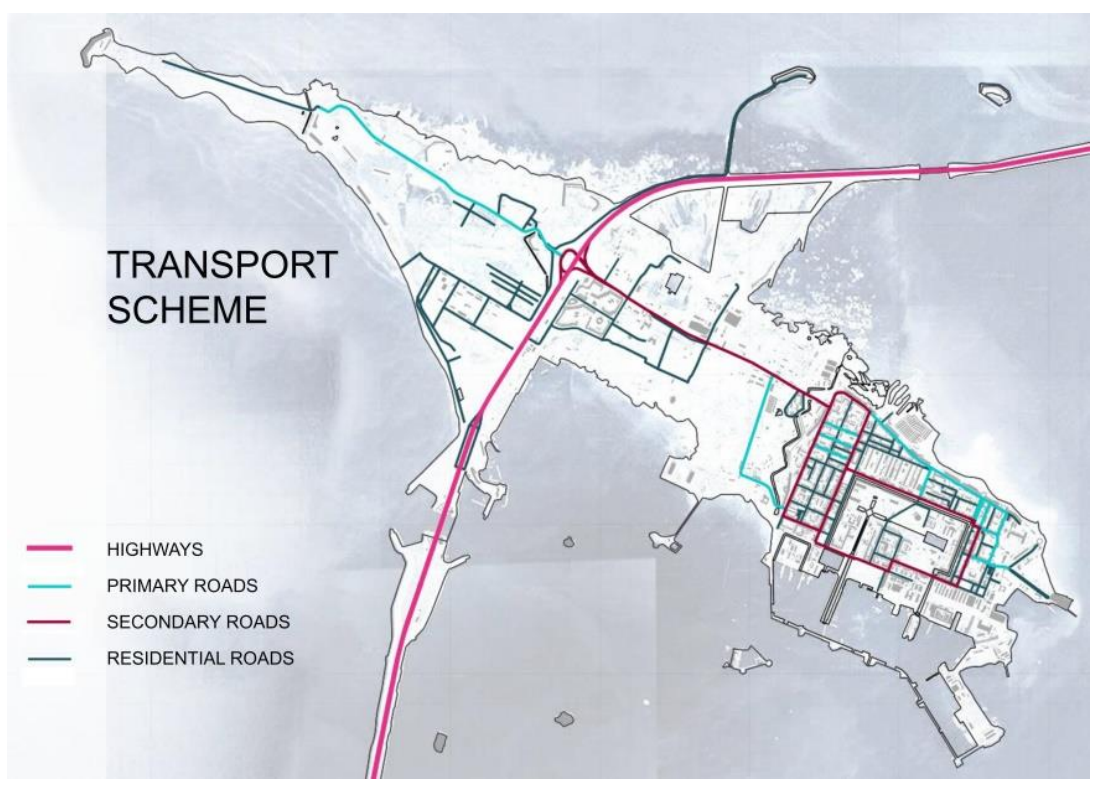

Fig. 1. Existing transport scheme.

At present, educational institutions, social services, medicine, sports, culture and recreation operate in Kronstadt, but according to the research, there is a lack of social infrastructure facilities, the capacity of existing facilities is below the normative needs of the population $[1,9]$.

There are also a number of problems that have formed historically: isolation from urban life in the western part of the island; poor condition of the monuments; underdeveloped transport accessibility; a large number of abandoned and unused territory.

The coastal zones and embankments of Kronstadt are the main potential of the city, however, at present, the city's openness to the sea is quite low. Most of the coastline of the historical center is occupied by military and shipbuilding enterprises. Kronstadt paradoxically turns out to be an island city with almost no access to water. Historically, coastal spaces were regarded as unsuitable for construction due to the high risk of flooding and became technically used warehouses, military or industrial territories.

52 military camps are located on the territory of the Kronstadt district of St. Petersburg, which occupy an area of 478.3 hectares, which is $25 \%$ of the area of the Kronstadt region. At the moment, the process of transferring a number of military and industrial facilities to the city, many of which are close to water, is underway. Kronstadt will get an opportunity and a place for new points of growth and development.

Kronstadt is less interesting for developers and potential consumers than many metropolitan areas. New housing is almost not being built here, retail and leisure are poorly developed, there is practically no class A and B office real estate segment, and the hotel business is extremely poorly developed for the tourist city. Existing tourism facilities are not interconnected in a single route, most of them are in an abandoned state, the entrance to many is still closed. The center of Kronstadt is characterized by limited access to the coastline, due to the presence in the city of military facilities, as well as port and shipbuilding enterprises: most of the coastline in the historic center is not accessible for visiting. There is a problem of pendulum migration. In Kronstadt there are no universities, a large shortage of jobs. Therefore, the majority of students and the working population are forced to travel, and subsequently move to St. Petersburg. 
At the same time, it can be noted that the city is very convenient for humans. Its planning structure, the scale of buildings and streets are proportionate and comfortable for a pedestrian. Kronstadt has unique physical, geographical and natural characteristics, a preserved historical structure and rich history. Major events are already being held here. It is planned to implement several major projects aimed at realizing the tourist potential of the territory, creating centers of labor attraction. On the periphery of the historical part of the city there are several spaces that have great potential, but are used very inefficiently: the banks of the Kronverksky Canal, Kabotazhnaya and Kupecheskaya Gavan, as well as a section of the northern coast of Kotlin along ul. Uprising, Petrovsky dock, as well as the area of the Leningrad pier, forts. Efforts are being made to increase the role of the city not only on a regional scale. Today, the Main Naval Parade is being held in Kronstadt - one of the largest events of the city, watched by thousands of tourists, it is planned to hold the International Naval Salon. Work is underway on the creation of the Patriot MilitaryPatriotic Park. Most of the western part of about. occupied by the territory of the Western Kotlin Wildlife Refuge. There is also the Bull Field airfield and minor sports, military and industrial facilities (Fig. 2).



Fig. 2. Support plan with the placement of objects of attraction.

\subsection{Problems of single industry cities}

Speaking about the former industrial, port and military cities, it can be noted that these are structures close to each other, having a number of similar features, the main of which is "the presence in the city of one or several enterprises of the same type belonging to the same industry, or serving one narrow segment of the industry market, while the rest of the city's enterprises serve only the internal needs of the city or the people living in it "[4]. Often such cities are called single-industry. 
World trends in the modern development of society and the economy indicate that the era of the industrial economy, dominated by industrial production, and the main factor in production was material wealth, began to lose strength. Today we are at a new - postindustrial - stage of social development, where the main changes are associated with changes in the structure of employment - there is a significant shift in favor of the service sector. The share of such services as medicine, education, storage services, reproduction and creation of knowledge, as well as entertainment industry has especially grown [2].

The described social and economic changes in the urban environment serve as the basis for identifying the main problems characteristic of previously prosperous industrial cities. They can be divided into several groups [3]:

- economic: a decrease in industrial production in the city (due to a decrease in demand for products or a lack of resources, including their appreciation); the transfer of enterprises outside the city or to other countries; active modernization of production, a decrease in employment in industrial production, as a result - an increase in structural unemployment and labor migration; high risk of long-term unemployment among industrial workers due to the existence of high retraining costs for work in the service sector;

- social: population decline (relocation to the suburbs or other cities), moreover due to the outflow of the most socially prosperous part of the population; low level of human capital (a small number of educational institutions); increased crime;

- infrastructure problems and land use problems: the formation of unused sites of former industrial and military territories (brownfields); the decline of public services in the central city; dilapidated buildings.

In formulating development strategies for the former military and industrial territories, this whole complex of problems must be taken into account.

One of the possible solutions is to continue the development of industry by changing the specialization to a more relevant one that meets the requirements of the modern economy, or using the latest technologies in an existing one [3]. However, this will only solve economic problems; over time, production will be forced to constantly catch up with progress, which is almost impossible. For successful further development, it is necessary to include elements of a post-industrial economy, restructure social infrastructure, work on the image and ecology of the city.

At the same time, for cities that want to partially transfer or completely abandon the industrial and military base, the main solution is development through culture and education, attraction of tourism and, as a consequence, investment [3]. This will give an impetus to the development of the economy, social infrastructure, create new jobs and lay the foundation for the further development of the territory. The main emphasis is on the following activities [4]: the development of research and development, innovative activities (including in the area of former industrial specialization); cultural development; the provision of social services, primarily in areas such as education and health; tourism development in various forms: leisure, sports, cultural, business tourism;

Urban revitalization projects are inseparable from the rehabilitation of the urban environment, new urban development initiatives.

Most often, it is impossible to start the process of revitalization at the same time throughout the city - this would require enormous resources, primarily economic. A much more realistic model is proposed in which, after a thorough analysis of the territory, the nodes of the strategic development of the city are selected [2]. They form growth points around themselves, create new infrastructure, attract investment and, as a result, contribute to the development of adjacent territories.

As noted earlier, the historical, architectural and natural resources of the territories have the greatest potential. Their intersection in one place is the most favorable space for creating a starting point for the growth of the city. Often the place of such concentration is 
the coastal territories. Due to its historical development, many sea embankments have turned into warehouses, under-utilized industrial and military territories. However, at present, in connection with the transition to a post-industrial economy, these spaces are beginning to be actively developed, and their development is acquiring historical and architectural value.

From the point of view of a city dweller, embankments are unique and especially attractive places around the world, therefore they are given special attention in the history of urban development. And therefore, any improvements in coastal spaces affect the perception of the quality of the urban environment. It can be argued that the embankments are one of the main urban symbols, the concentration of the "spirit of the place", their development and condition directly affects the image of the city. They play a large role in creating city identity codes. At the same time, coastal territories are very saturated with resources and opportunities - they contain many functions that contribute to attracting people and developing the economy. It can be as a service infrastructure - street cafes and snack bars, beaches and swimming pools on the water, sports grounds, and recreation areas, cultural spaces, business and residential areas.

\subsection{Analysis of the source data to identify new development nodes}

In the work on identifying potential points of attraction for Kronstadt, a field study, cartographic analysis, and analysis of geographic information systems were performed. As a result of this work, the following were compiled: a reference plan, transport schemes, functional schemes, landscaping schemes, a scheme of accessibility of the territory, schemes of social and business activity and points of attraction, and others.

SWOT. On their basis, as well as with the help of information studied earlier in the historical background, the strengths and weaknesses of the territory, its capabilities and threats were formulated (Table 1).

Table 1. SWOT analysis.

\begin{tabular}{|c|c|}
\hline Strengths & Weaknesses \\
\hline $\begin{array}{c}\text { Rich historical and cultural heritage } \\
\text { The preserved historical center and its } \\
\text { planning structure } \\
\text { Natural and landscape diversity, a large } \\
\text { number of landscaping } \\
\text { Unique geographical location } \\
\text { Attractive water resources, long coastline } \\
\text { Tourist attraction } \\
\text { Proximity to St. Petersburg } \\
\text { Airfield Availability }\end{array}$ & $\begin{array}{c}\text { Waterlogging of the territory } \\
\text { high risk of flooding, especially in the western } \\
\text { part } \\
\text { A large number of military camps, warehouses, } \\
\text { unused territory } \\
\text { Lack of communication between the western and } \\
\text { eastern parts of the island } \\
\text { Unsatisfactory condition of monuments and } \\
\text { historical center } \\
\text { Short-term tourism } \\
\text { Lack of public, business, residential, educational } \\
\text { and cultural facilities } \\
\text { Low intensity of use of the territory }\end{array}$ \\
\hline Opportunities & Threats \\
\hline $\begin{array}{c}\text { Adaptation of Windows for new functions } \\
\text { Revitalization of coastal spaces } \\
\text { Development of unused territories and } \\
\text { military camps } \\
\text { Water Sports Development } \\
\text { creation of alluvial territories } \\
\end{array}$ & $\begin{array}{c}\text { Dipressive territories } \\
\text { The loss of monuments } \\
\text { Lack of investment } \\
\text { Lower tourist flow } \\
\text { Damaging the ecosystem of the island } \\
\text { existing }\end{array}$ \\
\hline
\end{tabular}




\subsection{Requirements for public spaces}

The fundamental factors in creating nodal public spaces should be the meanings, goals, purpose of this space, identified in accordance with the needs of consumers, the requirements of comfort and safety, accessibility, and location features.

The requirements for such spaces will be the principles that influence the design of public spaces, which can be decomposed into four components in a certain hierarchy as they grow, where safety is a primary need (Fig. 3).

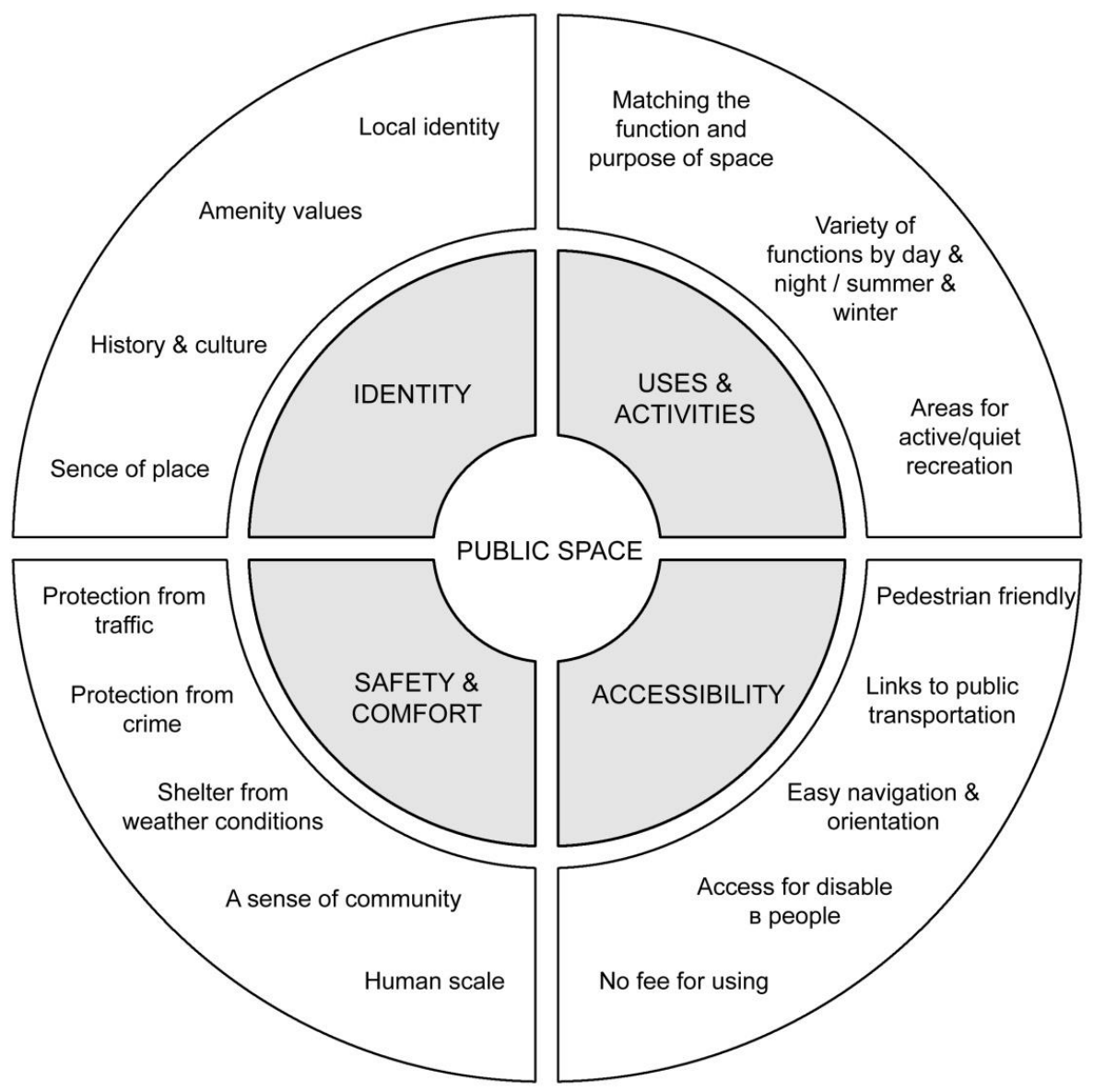

Fig. 3. Graphic model of factors affecting the quality of public spaces.

\subsection{Identification of the urban environment}

When forming nodes of active development, it is also necessary to identify the identification signs of the territory that will help to connect new areas with existing ones.

The most striking identification sign of the island is the naval and military subjects. It is found often and is aimed at reproducing the former greatness of the Russian fleet and, therefore, the associated exceptional importance of Kronstadt as a fortress city for Russia. Kronstadt as a city structure is very convenient for pedestrians. The high-density orthogonal street-road network provides the necessary circulation of traffic flows of vehicles, cars and pedestrians. The average street length of about $500 \mathrm{~m}$ is also very comfortable for humans. Kronstadt is characterized by low permeable quarters. This determines the openness and co- 
scale to the person of the urban structure, the uniform density of development. The urban development of Kronstadt was formed over three centuries, so the styles of different eras were reflected in the architectural appearance of the city. In architecture, there is often a 3fold division of the facade, pitched roofs of 20-30 ${ }^{\circ}$, a regular grid of windows, wide walls between them, blank walls. Most of the historic buildings are plastered and painted in calm shades, many houses are made of red and gray bricks and have no additional decoration.

\subsection{The main stages of the formation of the creation of new development nodes}

The basis for creating the concept of new attraction nodes was the analysis of the territory from the point of view of existing potential, the scheme of priority projects planned for implementation in the city of Kronstadt, provided by the government of St. Petersburg. It reflects the vision of the administration in the strategic areas of development of the city. The complementary materials were the SWOT analysis (Table 2), the support plan (Fig. 2) and the previously presented schemes (Figs. 1-4), as well as the factors of site identity and the requirements for the organization of public spaces. The experience of designing modern released coastal territories was studied. Examples include: Paper Island COBE in Copenhagen, Sørenga in Oslo, Noblessner in Tallinn, Aker Brygge in Spol in Oslo, The New Simac C.F. Møller and Effekt in Svenborg and others.

The following steps to create an enabling environment were also taken into account [13]:

1. The inclusion of the territory in the existing urban context:

determining the role of the node in the city system: the economic potential of the territory, determining the potential non-residential program:

- determination of the node potential with respect to transport infrastructure, the possibilities of developing local connectivity;

- identification of potential cultural and recreational programs, green corridors / links.

2. Identification capabilities of the territory:

- identification of as many specific terrain features as possible, anomalies, unusual conditions that can be developed and developed in the project;

- introducing "modernity" into the project: new elements, objects, spaces that can become a symbol of the future territory;

- the formation of a basic planning framework around the identified features of the territories and new nodes of attraction.

3. The structure of the territory:

- the creation of potential links both within the regions and with the adjacent territories, the green frame;

- relying on the identity of the place and nodes of public transport, determine the hierarchy and significance of relations, form a system of central places, nodes of attraction;

- to form urban ensembles, accents.

Focus on a specific group of consumers. Drawing up a portrait of a consumer will help to formulate his basic needs and desires.

Planning flexibility. Parts of the district should be able to easily unite and separate depending on the needs of developers and site planning. It is necessary to test the scenarios of a possible future.

\subsection{Revealing the location of public centers based on public spaces as possible nodes for the development of the city}

The identification of potential development nodes based on the creation of public spaces was carried out using a comprehensive analysis. The analysis of the territory in accordance 
with the basic requirements for public spaces, the presence of development potential, the required connectivity of the zones under consideration among themselves made it possible to determine the potential and possible places of promising public centers. The starting points for the development of the city were selected 4 large nodes that have the greatest potential and are currently either not built up or not used (Fig.4). They are supposed to be connected with each other through continuous green corridors, which, on the one hand, will connect the isolated western part of the island with the central and eastern ones, and on the other, they will add a new direction from north to south, combining the two designed embankments. All nodes gravitate towards water - as already mentioned, coastal spaces are the main undisclosed potential of Kronstadt. The main task of their creation is to intensify the economic, social and cultural development of the territory and, as a result, attract investment for the further growth of the city and the development of tourism. It is also necessary to combine the western and eastern parts of the island into a single tourist route, while maximally incorporating the existing points of attraction in the city and green spaces. Thus, the following problems are solved:

1) social - favorable diverse residential areas are created that are attractive to residents;

2) economic - create new jobs, tourism infrastructure, attracting investment and contributing to the economic growth of the territory;

3) image - previously unfavorable image of the city is transformed into a modern, environmentally friendly, which contributes to its further growth;

4) environmental - improving the natural environment in the city. Increasing the amount of landscaping and its connectivity in a single system;

5) architectural and urban planning - previously abandoned and unused lands are involved in the regeneration process, the potential of coastal territories and industrial architecture is developing.

It is important to note that, following the principle of identity, each district has its own unique characteristics.



Fig. 4. Layout of development nodes. 
The 1st node - territory limited by the Ring Road, South Kronstadt Road and the embankment. This section borders on the Patriot Military Patriotic Park and the reconstructed airfield. Given the proximity of the highway and convenient transport, air and sea links, this territory is provided for the Marine Salon. A feature of this territory is its frequent flooding, as it is located to the dam, so there are houses on the pantheons, hotel infrastructure, designed to serve the Marine Salon and business tourism. Given the proximity of large green areas, the slogan of this territory may be "ecology".

The second node is a promising alluvial territory in the north of the island. They are characterized by great openness to water and great opportunities for the use of the water front, the flexibility of architectural and urban solutions. A feature of this place will be a rowing canal - a unique structure designed for mass events, so the slogan of this site can be called "sport".

The 3rd node is a section limited by Admiral Greig Street, Kronstadt Highway, Zosimov Street, Martynov Street and Petrovsky Canal. This territory, due to its location, open coastline and close access to the historical center, is intended for the tourist and recreational cluster. There is a number of former industrial buildings, a fort, a number of unique structures - museums, business centers, an aquarium - are being designed that create an environment around itself for the further growth of the city. The slogan of this territory is "tourism".

The 4th node is a section of the Marine Plant and the adjacent territory. At the moment, the plant has almost stopped working and in its place unorganized warehouses are being formed. Due to the large number of industrial buildings that have been preserved, the spirit of the place, this territory is best suited for creating an innovative center designed for the education and communication of not only the city's residents, but also its visitors.

\section{Conclusions}

In conclusion, we can say that the modern city can no longer develop, relying on only one area of activity. In the era of post-industrial development, an integrated approach is needed to remove the territory from the state of stagnation. This approach includes urban planning and social studies, studying the experience of other countries.

The further growth of single-industry cities through the growth of industry is a dead end. The development of the information sphere - the industry of knowledge, tourism, culture, business, and the service sector — seems much more promising.

It is required to determine the uniqueness of the territory, its difference from the neighboring ones, to identify the main resources and potential places of growth.

It is necessary to create new unique areas, while linking them with existing ones. They will create new jobs and diversify the environment of a historic military city.

It is also necessary to build unique architectural objects - natural landscape or buildingmagnets, which would help attract tourists and economic development of the territory.

Since Kronstadt is a small city, it is important to create a continuous green frame that connects all the important places of the city and is convenient for pedestrians and cyclists.

It is necessary to equip and functionally saturate the coastal territories, as the intersection of economic, social, cultural and tourist flows.

It is required to reconstruct and preserve the historic buildings of Kronstadt, endowing them with new functions and meanings. Point architectural accents on wastelands in the historical center are possible.

Often the coastal space becomes the central element and the intersection of these events. Its arrangement as a new "face of the city" becomes not only an important part of the marketing strategy, but also a place of concentration of economic, social, cultural and 
tourist flows. Therefore, the development of coastal territories is a priority in the reorganization of former industrial and military cities.

\section{References}

1. Kronstadt Vision 2040. Issuu - Digital Publishing Platform https://issuu.com/mlaplus/docs/sborka_6_11 (accessed: 01/10/2020)

2. R. Marshall, Waterfronts in post-industrial cities (Spon Press, London, 2001)

3. I. Starodubrovskaya, et al., Scientific works, Institute of Economic Policy named after E. T. Gaidar, № 148 (2011)

4. I.O. Moskalenko, Actual Issues of Economics and Management: Materials of the Intern. Scientific Conf. II, 157-160, RIOR, Moscow (2011)

5. S.I. Elagin, Kronstadt Bulletin, № 1, 3, 5, 6 (1866)

6. V. Ya. Peasants, Kronshtadt: Fortress, city, port, 160, Ostrov, St. Petersburg (2002)

7. G.F. Petrov, Kronshtadt: Essay on the history of the city (2nd ed., p. 333, Lenizdat, 1985)

8. General information on the Kronstadt district. Official site of the administration of St. Petersburg https://www.gov.spb.ru/gov/terr/reg_kronsht/information/ (date of access: 05.01.2020)

9. Updating the concept of urban development on. Kotlin, St. Petersburg State Institution Scientific Research Center for General Plan of St. Petersburg (2018)

10. The list of objects of cultural heritage and identified objects of cultural heritage on the territory of St. Petersburg. Government of St. Petersburg. Committee on State Control, Use and Protection of Historical and Cultural Monuments http://kgiop.gov.spb.ru/uchet/list_objects/ (accessed: 01/05/2020)

11. D.V. Basova, Comparative Politics, № 4 (2014)

12. Aker Brygge Masterplan, SPOL Architects https://spolarchitects.com/projects/akerbrygge/ (accessed: 01/15/2020)

13. Residential areas for convenient cities. Planning Principles, MLA + Architects https:/www.mlaplus.com/wp-content/uploads/2019/02/Greenfield-designprinciples.pdf

14. The principles of the formation of the living environment, Ostozhenka, KORTROS, Arch, Moscow (2016)

15. A.S. Kuskov, Yu.A. Jaladyan, Basics of tourism (p. 400, Knorus, Moscow, 2008)

16. S.M. Gordeeva, V.N. Malinin, V. YuMalinina, Society. Wednesday. Development, № 3, 251-256 (2010)

17. N. R. Doroshchuk, International Scientific Review, № 21 (31) (2016) 